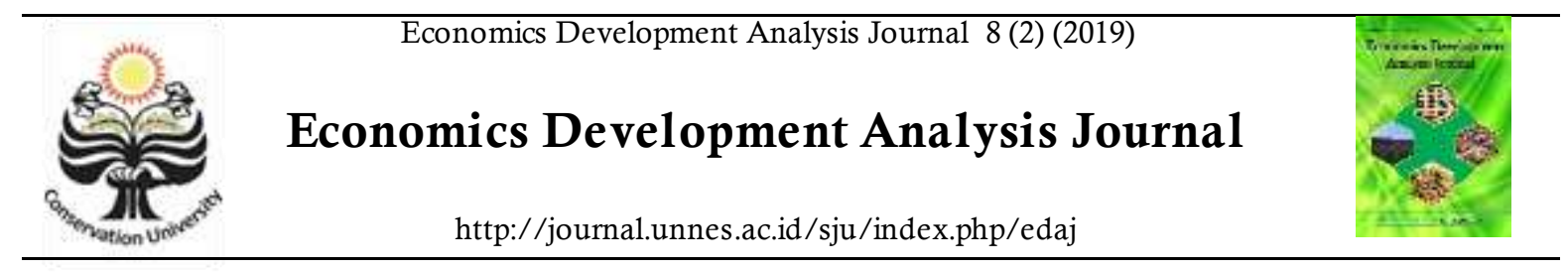

\title{
Analysis of Indonesia's Inflation Using ARIMA and Artificial Neural Network
}

\author{
Fauzi Insan Estiko ${ }^{1 凶}$, Wahyuddin S. ${ }^{2}$
}

${ }^{1}$ Department of Economics, Hanyang University, Seoul, South Korea

${ }^{2}$ Magister of Information System, Universitas Komputer Indonesia, Bandung

\section{Article}

\section{Information}

\section{History of Article}

Received January 2019

Accepted March 2019

Pusblished May 2019

Keywords: ARIMA, Neural

Network, Indonesia's inflation, forecast, trend, RMSE.

\begin{abstract}
This study aims to find if there is any interesting trend in Indonesia's inflation and to compare forecast performance of autoregressive integrated moving average (ARIMA) model to artificial neural network (ANN) in the case of Indonesia's inflation. We use year-on-year monthly Indonesia's inflation data from 2006:12 to 2018:12 released by Bank Indonesia (BI) and the Indonesian Central Bureau of Statistics (CBS). We divide the series into 3 data series to capture the trend in the inflation (i.e DS1, DS2 and DS3). The data set 1 (DS1) covers data from 2006:12 to 2014:08, DS2 from 2006:12 to 2018:12, dan DS3 from 2010:12 to 2018:12. The series is then processed using the standard ARIMA method and ANN model. We found that short term lagged-inflation (backwardlooking) variable has lesser effect on inflation compared to the more recent series. We also found that the ANN model outperforms the ARIMA model in forecasting inflation for each respective series by analysing its Root Mean Squared Error (RMSE).
\end{abstract}




\section{INTRODUCTION}

Inflation has always been attracting interests of many researchers. Many of them have carried out studies on inflation estimation whereas others on inflation forecasting. Each country may have its own economic characteristics so that a different inflation model may be required. Moreover, inflation is a dynamical system so that its characteristic may change over time. This paper is motivated by the following research questions in the case of Indonesia.

First, we want to know whether there is certain interesting trend in Indonesia's inflation. Second, whether a single autoregressive integrated moving average (ARIMA) model, which is estimated based on inflation data from the beginning of Inflation Targetting Framework (ITF) implementation up to the present time in Indonesia, can effectively be used for inflation forecasting one year ahead during different time frames in Indonesia. Third, whether artificial neural network (ANN) model enhances performance of the ARIMA models in forecasting inflation in Indonesia.

Researchers have studied sources of inflation in Indonesia which are invaluable for policy making. They developed inflation estimation models based on economics theory and used them for analyzing determinant factors of Indonesia inflation. (Reza Siregar and Gulasekaran Rajaguru, 2005) examines sources of inflation in Indonesia during the period of 1985-2001. The working model is based on a general expression for domestic inflation. It suggests that domestic inflation is influenced by fluctuations in domestic income, domestic and foreign interest rates, domestic money supply, and expected depreciation of the local currency. They proposed an Autoregressive Distributed Lag (ARDL) model for estimation, with a constant and white noise error processes, but without incorporating any error correction component in the regression. During the period of July 1997 - December 2001, the montly regression results confirm the substantial roles of expected depreciation of rupiah, money supply, and domestic interests in explaining inflation rate. The most significant and persistant contributor to the increase in the overall inflation is the base money. (Rizki E. Wimanda et al., 2011) investigate the dynamic of inflation in Indonesia using monthly data from 1980:1 to 2008:12. They employ a hybrid version of the New Keynesian Phillips curve (NKPC) which incorporate both expected future inflation and lagged inflation. The proposed estimation model provides econometric evidence which suggests that consumer price index (CPI) inflation in Indonesia is significantly determined by both backward-looking forward-looking expectations. Their estimates indicate that CPI inflation substantially determined by backward-looking inflation, forward-looking inflation, output gap, exchange rate, and money growth. The backward expectation has larger weight than the forward rate leading to the conclusion that Indonesia's inflation possesses considerable inertia.

(Deni Sri Haryati et al., 2014) analyzed Indonesia inflation during the period 1969-2009 based on economics theory. Using data during the period 2001-2014, (Aloysius Deno Hervino, 2015) showed that inflation dynamics in Indonesia could be explained by the hybrid model of NKPC. The variable of forward-looking has significant effect on inflation dynamics, but the variable of output gap has no significant effect on inflation dynamics. (Ulfatul, 2017) analyzed the influence of interest rate, exchange rate, inflation expectations, output gap, and gross domestic product (GDP) on inflation in Indonesia during the period 2006:01-2016:06. She used Vector Error Correction Model (VECM) and the results indicated that in short term, the BI rate, inflation expectation, exchange rate, and output gap significantly affect inflation whereas in long run the variables affecting inflation rate are $\mathrm{BI}$ rate and inflation expectation. (Idah Zuhroh et al., 2018) analyzed the dynamic impact of foreign exchange reserves, money supply, and exchange rate on inflation by using Vector Autoregression (VAR). They used monthly data from 2009:06 to 2016:11. They concluded that money supply and exchange rate have significant effect on inflation whereas foreign exchage reserve has insignificant effect on 
inflation. The biggest contributor of inflation is exchange rate beside inflation itself.

On the other hand, inflation forecasting has also attracted researchers worldwide. Few inflation forecasting models have been proposed. (Saeed Moshiri and Norman Edward Cameron, 2000) compare forecasting performances of econometric structural models, time series regression models, and artificial neural networks (ANN) models, by using monthly data which covers the period of 1970:1-1994:12 from the CANSIM databank constructed by Statistics Canada. The time series regression models are ARIMA, Vector Autoregression (VAR), and a Bayesian Vector Autoregression (BVAR) models. The results revealed that the ARIMA model provided the smallest root mean square error (RMSE) in static forecasts whereas the ANN model, which uses the same input vector as that of the ARIMA model, yielded the smallest RMSE in dynamic forecasting twelve months ahead. (Emi Nakamura, 2005) investigated the usefulness of a neural network (NN) model for forecasting inflation. She evaluated the importance of early stopping and pre-processing. She followed up on (Norman R. Swanson and Halbert White, 1997) conjecture that this type of technique is probably of interest given the relative inability of other types of model selection criteria such as the Schwarz Information Criterion (SIC) to select the optimal forecasting model. She, like (James H. Stock and Mark W. Watson, 1998), considered only univariate inflation forecasting models and used the U.S. GDP deflator from 1960:Q1 to 2003:Q3. Given the limitations of the data, she chose a simple architecture with very minimal search over alternative network architectures. The forecasting model incorporates two lags (lag 1 and lag 2) of inflation, two hyperbolic tangent functions, input weights, layer weights, and biases. She carried out forecasting performance comparison with a linear autoregressive (AR) models with lag lengths between 1 and 8 . The results indicated that the NN model provided smaller mean square error (MSE) than the AR models for forecasting inflation for one to four quarters horizon.
Some researchers have published their works on Indonesian inflation forecasting. The Bob-Jenkins methodology has been used to estimate Indonesian inflation by (Bunyamin and Nevi Danila, 2011), (Suparti et al., 2014), and (Suparti and Faridatus Sa'adah, 2015). (Bunyamin and Nevi Danila, 2011) estimated inflation in Indonesia using yearly inflation data in the period $1980-2008$. They concluded that the best model was $\mathrm{AR}(2)$ with the value of constant is 11.05 and the value of the lag 2 coefficient is -0.104.(Suparti et al., 2014) conducted analysis of Indonesian inflation in the period 2006:12 to $2013: 12$ and they concluded that the best inflation estimation model is $\operatorname{ARIMA}([1,12], 1,0)$. (Suparti and Faridatus Sa'adah, 2015) reported the $\operatorname{ARIMA}([1,12], 1,0)$ with outlier is better than the $\operatorname{ARIMA}([1,12], 1,0)$ model without outlier. (Warsito and Mukid, 2015) developed an inflation estimation model using ANN of which the input variables are the same of $\operatorname{ARIMA}([1,12], 1,0)$. The Indonesian year-on-year inflation data during the period 2006:12 to 2014:08 is used. They concluded that the ANN model yielded smaller MSE for out-ofsample.

None those articles address the problems described in the first paragraph. In other words, we need to answer whether the model is still relevant for estimating Indonesia's inflation in the last several years. Whether one of the most popular model used for forecasting, ARIMA, is a better fit to forecast inflation in Indonesia in comparison to Neural Network model. This paper aims to answer the research questions described in the first paragraph. This paper contributes to the literature of inflation estimation and inflation forecasting by confirming effectiveness of the models and further development of inflation forcasting based on ANN.

\section{RESEARCH METHOD}

This paper uses two types of estimation and forecasting modelling i.e. sole standard ARIMA model and artificial neural network (ANN) model. In the following, ARIMA model 
and ANN model are reviewed, data sources and data analysis are described, and approaches to answer the research questions are introduced.

An ARIMA (p,d,q) process is denoted as follows:

$\pi_{t}=\theta+\alpha_{1} \pi_{t-1}+\cdots+a_{p} \pi_{t-p}+\beta_{0} \mu_{t}+\cdots+$

$\beta_{q}$

where $\theta$ represents constant term, $\pi_{t}$ represents inflation, and the model contains autoregressive terms up to $\mathrm{p}$ lags and moving average terms up to $\mathrm{q}$ lags. $\alpha_{i}$ is coefficient of the autoregressive term, where $i=1,2, \cdots, p$. Coefficient of the moving average term is denoted by $\beta_{j}$, where $j=$ $0,1,2, \cdots, q$.

The model is derived using the BobJenkins methodology which consists of 4 stages: identification, preliminary estimation, final estimation, and diagnostic checking. The flowchart is illustrated in Figure 1. It starts with stationary inspection, and it ends with normality test. The procedure is as follows.

First, stationary inspection is carried out using Autocorrelation function (ACF), Partial Autocorrelation function (PACF), augmented Dickey-Fuller (ADF) test, and McKinnons's test statistics for unit root test, and a tentative ARIMA model is identified. If the original variable is not stationary, we calculate the first difference of the variable. If the first difference of the variable is not stationary, we further calculate the second difference of the variable. We will move to the next step only if the variable is stationary.

Second, a preliminary ARIMA model is estimated using the Akaike information criteria (AIC). The lag order ( $p, q)$ that minimizes the AIC is then selected.

Third, the model's stability as well as the significance of its parameters are checked using the z-test. If both these two tests are successful, we proceed to the next step.

Fourth, a series of diagnostic tests are carried out. We evaluate the residuals for uncorrelatedness using the Ljung-Box (LB) test. The normality is assessed using Shapiro-Wilk normality test and Q-Q plot.

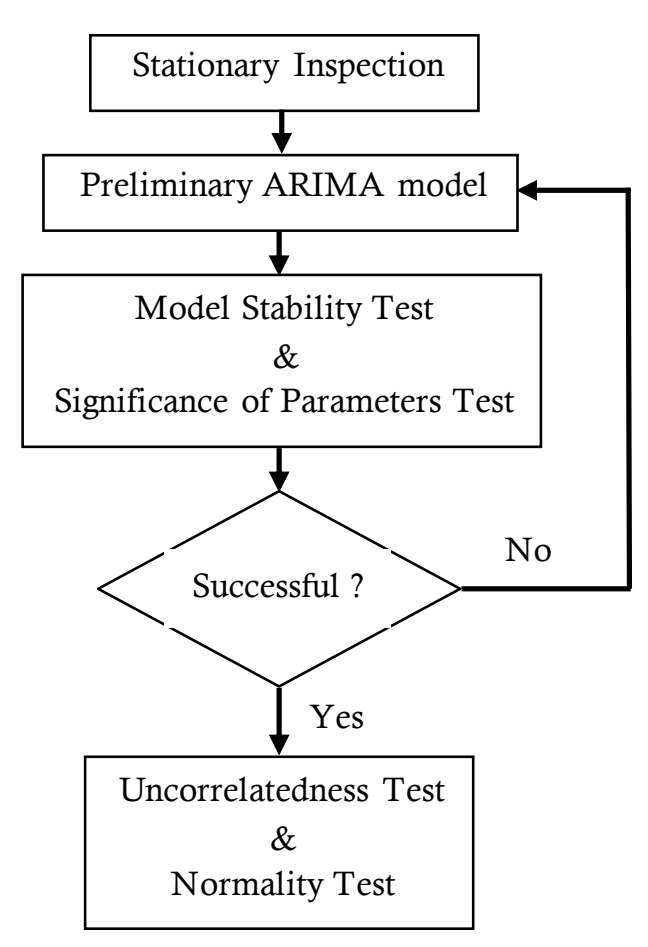

Figure 1. Flowchart of ARIMA Modelling.

For the ANN model we borrow the structure from (Emi Nakamura, 2005) in which inflation estimate $\hat{\pi}_{t}$ is given in equation (2).

$$
\hat{\pi}_{t}=L_{1} \tanh \left(u_{1}\right)+L_{2} \tanh \left(u_{2}\right)+b_{3}
$$

where: $u_{1}=\left(w_{1} \pi_{t-1}+b_{1}\right)$ and $u_{2}=\left(w_{2} \pi_{t-1}+\right.$ $\left.b_{2}\right) . w_{h}, b_{h}$, and $L_{h}$ denote input weight vector, input bias constant, and output weight constant, respectively. $b_{3}$ represents an output bias constant. Originally Nakamura used two input variables i.e. $\pi_{t-1}$ and $\pi_{t-2}$. We modified it by using 4 input variables. Moreover, instead of using hiperbolic tangential we used sigmoid function as activation function.

We used monthly data of year-on-year inflation from December 2006 to December 2018 as shown in figure 2. This data was collected from Bank Indonesia ("BI," n.d., 2018) and the Indonesian Central Bureau of Statistic (CBS) ("Badan Pusat Statistik," n.d., 2018). To answer the research questions, we splited the data in to 3 data sets (DS). The data set 1 (DS1) covers from 2006:12 to 2014:12, DS2 from 2006:12 to 2018:08, and DS3 from 2010:12 to 2018:12. 
In the DS1, data from 2006:12 to 2013:12 was used for model estimation whereas the data from 2014:01 to 2014:08 was used for forecasting. In the DS2, the data from 2006:12 to 2017:12 was used for estimation and the rest was for forecasting. In the DS3, data from 2010:12 to 2017:12 is used for model estimation and the rest was used for forecasting.

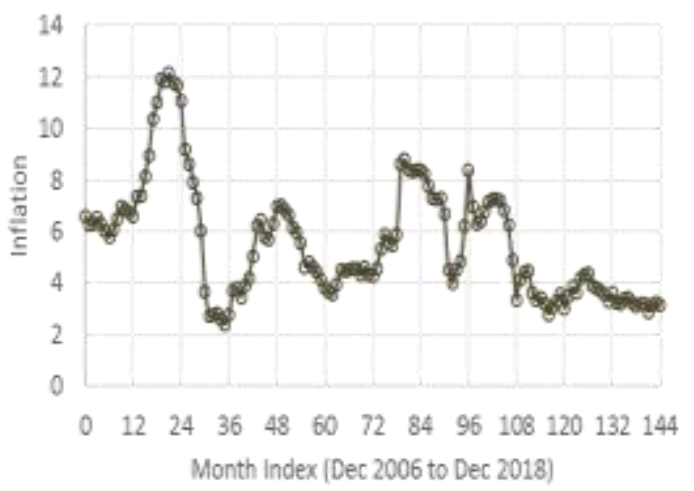

Figure 2. Inflation Data from Dec 2006 to Dec 2018 (BPS, 2018) (BI, 2018).

The first research question and the second research questions are answered by first making three ARIMA models for the three data sets and then conducting further dedicated analysis for each research question. ARIMA 1 is obtained by processing DS1, ARIMA 2 is derived from DS2, and ARIMA 3 is calculated from DS3. We propose an approach to extract inflation trend by analyzing coefficient values of autoregressive terms, and use a postulate that the larger the coefficient value of the corresponding autoregressive term means that the corresponding term gives larger effect to the present inflation.

In order to study effectiveness of each ARIMA model for inflation forecasting one year ahead, the three ARIMA models are used to forecast inflation and their performances are compared. Performances are evaluated in terms of root mean squared error (RMSE) and mean percentage error (MPE). Smaller RMSE dan smaller MPE imply a better performance.

Finally, ANN models are made based on the three ARIMA models. Input variables of the ARIMA model is used as the input variables for the corresponding ANN model. ANN algorithm is used to optimally determine values of the coefficient of autoregressive terms. Performance comparison study between ARIMA and ANN is carried out by comparing RMSE and MPE.

\section{RESULTS AND DISCUSSION}

First of all, stationarity of the time series data was assessed using augmented DickeyFuller (ADF) test and Mckinnons's test, and their $p$-values are evaluated. Significance of coefficients was analyzed using z-test (z-value, $p$ value), and the AIC value is recorded. For independence analysis, the Box-Ljung (BL) test (X, p-value) is implemented. The Shapiro-Wilk normality test was carried out (W, p-value). All those statistical tests results are listed in table 1. In the table, we classified the statistical tests into stationarity, independence, and normality categories.

From the stationary test statictics we know that variables in ARIMA 1, ARIMA 2, and ARIMA 3 are all stationary. L-1 and L-12 represent lag 1 and lag 12 , respectively. The significance of coefficient test statistics indicate that only lag 1 and lag 12 are significant. So that the other lag terms are neglected. The BL-test results show that the residual of ARIMA 1, ARIMA 2, and ARIMA 3 are all uncorrelated. Finally, normality test results demonstate that residual distribution of each ARIMA model is close to normal.

After conducting the procedure according to the Bob-Jenkins method, we obtained three different ARIMA models from the three data sets (DS1, DS2, DS3) of inflation. However, the three ARIMA models have the same structure as given in equation (3).

$$
\pi_{t}=\frac{e_{t}}{\left(1-a_{1} B-a_{12} B^{12}\right)(1-B)}
$$

where $B^{i}$ and $a_{i}$ denote operator of lag " $i$ " and its corresponding parameter. Recall that $a_{1}$ represents the corresponding parameter of lag 1 operator and $a_{12}$ denotes the corresponding parameter of lag 12 operator. Table 2 lists the parameter values of each ARIMA model. 
Table 1. Statistics Test Values

\begin{tabular}{|c|c|c|c|}
\hline \multirow{2}{*}{ Test } & \multicolumn{3}{|c|}{ ARIMA models } \\
\hline & ARIMA 1 & ARIMA 2 & ARIMA 3 \\
\hline \multicolumn{4}{|l|}{$\begin{array}{l}\text { Stationarity test } \\
\text { statistics }\end{array}$} \\
\hline $\mathrm{ADF}$ & 0.04 & 0.03 & 0.03 \\
\hline Mckinnons & 0.04 & 0.03 & 0.03 \\
\hline \multicolumn{4}{|l|}{$\begin{array}{l}\text { Significance } \\
\text { test statistics }\end{array}$} \\
\hline z-value (L-1) & 4.0 & 4.2 & 2.4 \\
\hline$p$-value( L-1) & $6.53 e-5$ & $2.63 e-5$ & 0.018 \\
\hline z-value (L-12) & -2.8 & -4.8 & -3.6 \\
\hline p-value (L-12) & $5.46 \mathrm{e}-3$ & $1.89 \mathrm{e}-6$ & $3.6 \mathrm{e}-4$ \\
\hline AIC & -120.7 & -174.4 & -94.1 \\
\hline \multicolumn{4}{|l|}{$\begin{array}{l}\text { BL-test for } \\
\text { independence } \\
\text { analysis }\end{array}$} \\
\hline $\mathrm{X}^{2}$ & 16.512 & 30.61 & 34.60 \\
\hline$p$-value & 0.8 & 0.1 & 0.04 \\
\hline \multicolumn{4}{|l|}{ Normality } \\
\hline W & 0.94 & 0.93 & 0.90 \\
\hline$p$-value & 0.0004 & $5.21 \mathrm{e}-6$ & $4.58 \mathrm{e}-6$ \\
\hline
\end{tabular}

On the other hand, the parameter of lag 12 operator in ARIMA 3 is smaller than that in ARIMA 2. However, ARIMA 1 has the smallest parameter of lag 12 operator among them. This implies that there is no consistent trend of significance level of lag 12. Interpretation of this results will be given at later part of this section.

Table 2. Parameter Values of ARIMA Models.

\begin{tabular}{cccc}
\hline \multirow{2}{*}{ Parameter } & \multicolumn{3}{c}{ ARIMA models } \\
\cline { 2 - 4 } & ARIMA1 & ARIMA2 & ARIMA3 \\
\hline$a_{1}$ & 0.414 & 0.336 & 0.238 \\
$a_{12}$ & -0.31 & -0.372 & -0.353 \\
\hline
\end{tabular}

Source: Data Processed

From table 2 it is obvious that the corresponding parameter of lag 1 operator in ARIMA 3 is smaller than that in ARIMA 2. Moreover, the corresponding parameter of lag 1 operator in ARIMA 2 is smaller than that in ARIMA 1. In this sense, it can be said that the significance level of lag 1 possesses a consistent decreasing trend. Figures 3 to 5 plot inflation forecasting results in the sense of pseudo out of sample forecasting. The horizontal axis represents time in month index. The month index 3, 6, 9, and 12 refers to March, June, September, and December, respectively. The vertical axis represents inflation rate. The solid lines represent the observed actual inflation whereas the broken ones express the predicted values.

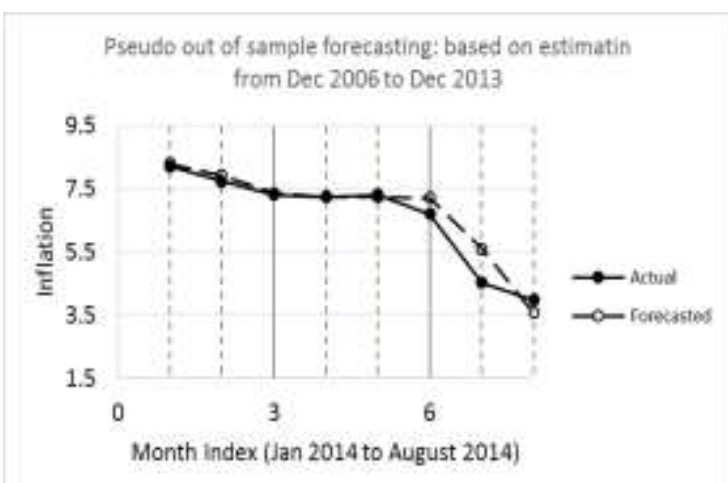

Figure 3. Inflation Forecasting Using ARIMA1.

In figure 3, pseudo out of sample forecasting results from January 2014 (month 1) to August 2014 (month 8) using the ARIMA1 model is plotted. We can observe that the ARIMA1 model can forecast well the inflation of January, February, March, April, and May. Yet, it's forecasted values deviate from the actual values in June, July, and Ausgust 2014. The actual inflation decreases gradually from 8.22 in January 2014 to 7.32 in May 2014. But it decreases drastically to 6.7 in June, and 3.99 in August 2014. Overall, the inflation records fall of 4.23 from January to August 2014.

In figure 4, pseudo out of sample forecasting results from January 2018 (month 1) to December 2018 (month 12) using the ARIMA2 model is plotted. We can observe that the ARIMA2 model can forecast well the inflation of January, February, March, April, May, June, July, and August. Yet, it's forecasted values deviate from the actual values in September and October 2018. The actual inflation fluctuates between the highest value of 
3.41 in April and the smallest value of 2.99 in September. The inflation fluctuation fange is 0.53. A drastic fall occurs from August to September, and we can notice a large negative deviation between the actual inflation and predicted inflation exists in September. Conversely, a drastic rise occurs from September to October, and we see a large positive deviation between the actual inflation and predicted inflation.

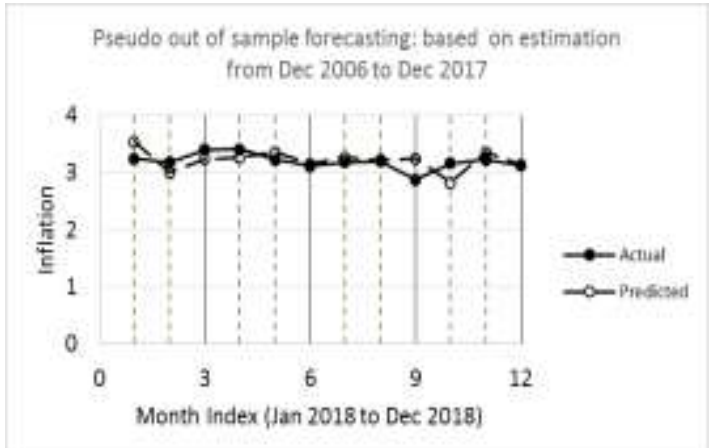

Figure 4. Inflation Forecasting Using ARIMA2.

In figure 5, pseudo out of sample forecasting results from January 2018 (month 1) to December 2018 (month 12) using the ARIMA3 model is plotted. The actual inflation is the same with that in figure 4 . We can observe that the ARIMA3 model can forecast well the inflation of January, February, March, April, May, June, July, and August. Yet, it's forecasted values deviate from the actual values in September and October 2018.

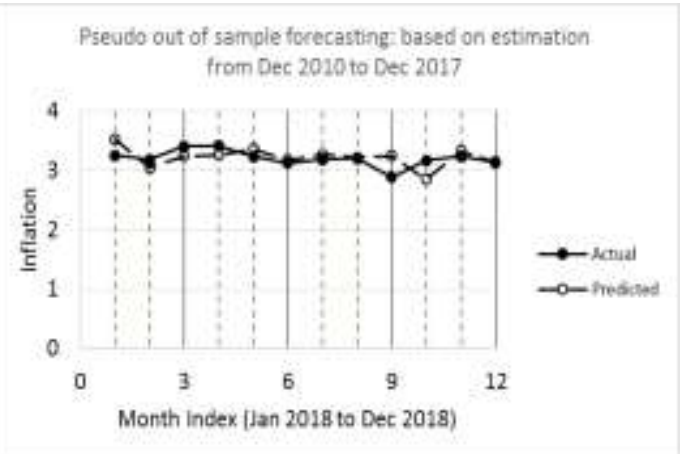

Figure 5. Inflation Forecasting Using ARIMA3.

These phenomena are the same as those in figure 4. A drastic fall occurs from August to September, and we can notice a large negative deviation between the actual inflation and predicted inflation exists in September. Conversely, a drastic rise occurs from September to October, and we see a large positive deviation between the actual inflation and predicted inflation. Table 3 lists up inflation forecasting performance indeces (PI) values of the three ARIMA models. The RMSE of ARIMA3 is smaller than that of ARIMA2. Subsequently, the RMSE of ARIMA 2 is smaller than that of ARIMA1. In the case of MPE, the similar results are obtained. With regard to both RMSE and MPE, ARIMA3 provides better forecasting performance than ARIMA2 and ARIMA1

Table 3. Forcesting Performances of ARIMA Models

\begin{tabular}{cccc}
\hline \multirow{2}{*}{$\begin{array}{c}\text { Performance } \\
\text { Index }\end{array}$} & \multicolumn{3}{c}{ ARIMA models } \\
\cline { 2 - 4 } & ARIMA1 & ARIMA2 & $\begin{array}{c}\text { ARIMA } \\
3\end{array}$ \\
\hline RMSE & 0.452 & 0.193 & 0.182 \\
MPE & -2.993 & -0.743 & -0.510 \\
\hline
\end{tabular}

Source : Data Processed

The above results indicate that the $\operatorname{ARIMA}([1,12], 1,0)$ models can be used for estimation and forecasting of inflation from the three different time ranges, but with different parameter values. Once again, we note that ARIMA3 gives better forecasting performance of inflation one year ahead during the same periode from January 2018 to December 2018 than ARIMA 2. Next, ANN models were developed in order to enhance forcasting performance of each ARIMA model.

Input variable for each ANN model is $\left[\pi_{t-1}, \pi_{t-2}, \pi_{t-12}, \pi_{t-13}\right]$. This input variable of each DS is substituted in to equation (2) and all ANN parameters were calculateusing neural network function. We used one neuron in ANN1 model for DS1 and two neurons in both ANN2 and ANN3 models for DS2 and DS3, respectively. Parameter values of the ANN models are listed in table 4 . We have input weights $w_{h i}$, input bias weights $b_{h}$, output weights $w_{o h}$, and output bias weight $b_{o}$. Here $i$ 
and $h$ denote input number and hidden neuron number, respectively. The simbol " $o$ " stands for output.

From table 4, we can express the ANN1 as in equations (4.1) to (4.5). The simbol Sig denotes Sigmoid function. The ANN2 and ANN3 can also be expressed in the same way.

$$
\begin{aligned}
\hat{\pi}_{t}= & 1.5645\left\{\operatorname{Sig}\left(u_{1}\right)+\operatorname{Sig}\left(u_{2}\right)+\operatorname{Sig}\left(u_{3}\right)+\right. \\
& \left.\operatorname{Sig}\left(u_{4}\right)\right\}-0.2219 \ldots \ldots \ldots \ldots \ldots \ldots . . .(4.1) \\
u_{1}= & \left(3.6549 \pi_{t-1}-1.449\right)(4.2) \ldots \ldots \ldots \ldots(4.2) \\
u_{2}= & \left(-0.9715 \pi_{t-2}-1.449\right) \ldots \ldots \ldots \ldots . . .(4.3)
\end{aligned}
$$

$$
\begin{gathered}
u_{3}=\left(-1.1679 \pi_{t-12}-1.449\right) \\
u_{4}=\left(0.9674 \pi_{t-13}-1.449\right) \ldots
\end{gathered}
$$

Figures 6 to 8 plot inflation forcasting results by using the ANN models. All the time frames and figure legends are the same with the corresponding ones in figures 3 to 5 . From figure 6 , we can see that the ANN1 model can forecast

\begin{tabular}{|c|c|c|c|}
\hline \multirow{2}{*}{ Parameter } & \multicolumn{2}{|c|}{ NN models } & \multirow[b]{2}{*}{ ANN3 } \\
\hline & ANN1 & ANN2 & \\
\hline \multicolumn{4}{|c|}{ Input weight } \\
\hline$w_{11}$ & 3.6549 & -2.950 & -1.3289 \\
\hline$w_{12}$ & -0.9715 & 0.3044 & 1.5142 \\
\hline$w_{13}$ & -1.1679 & 1.4179 & 1.2126 \\
\hline$w_{14}$ & 0.9674 & -0.0407 & -0.3208 \\
\hline$w_{21}$ & & -4.2905 & 2.5882 \\
\hline$w_{22}$ & NA & 2.9954 & 0.9483 \\
\hline$w_{23}$ & & -1.0741 & -0.0096 \\
\hline$w_{24}$ & & -4.3645 & 1.0381 \\
\hline \multicolumn{4}{|c|}{ Input bias weight } \\
\hline$b_{1}$ & -1.449 & 0.6929 & -1.5084 \\
\hline$b_{2}$ & NA & 2.0931 & -1.4812 \\
\hline \multicolumn{4}{|c|}{ Output weight } \\
\hline$w_{o 1}$ & 1.5645 & -1.4282 & -1.7371 \\
\hline$w_{o 2}$ & NA & -0.3646 & 1.3846 \\
\hline \multicolumn{4}{|c|}{ Output bias weight } \\
\hline$b_{o}$ & -0.2219 & 1.3068 & 0.0692 \\
\hline
\end{tabular}
well the inflation of January, February, March, April, May, July, and August 2014. Only in June that the forecasted value deviates from the actual value.

Table 4. Parameter Values of ANN Models. 


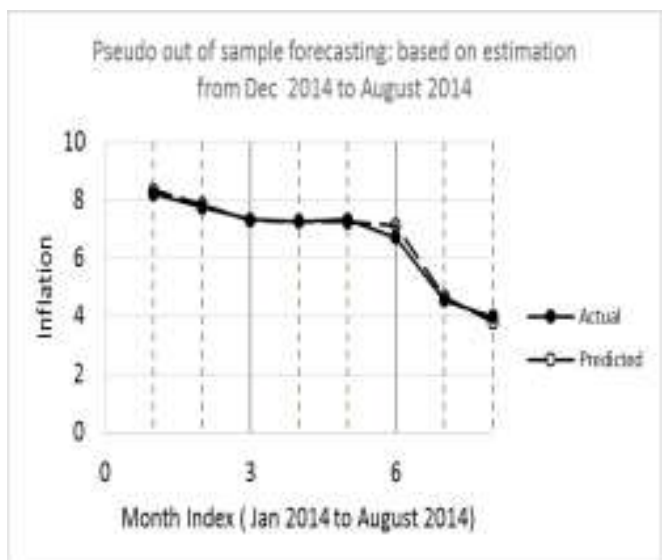

Figure 6. Inflation Forecasting Using ANN1: DS1

From figure 7, we can see that the ANN2 model can forecast well the inflation of January, February, March, April, May, June, July, and August 2018. In September and October the forecasted values deviate from the actual values. These results demonstrate similar pattern as that in figure 4.

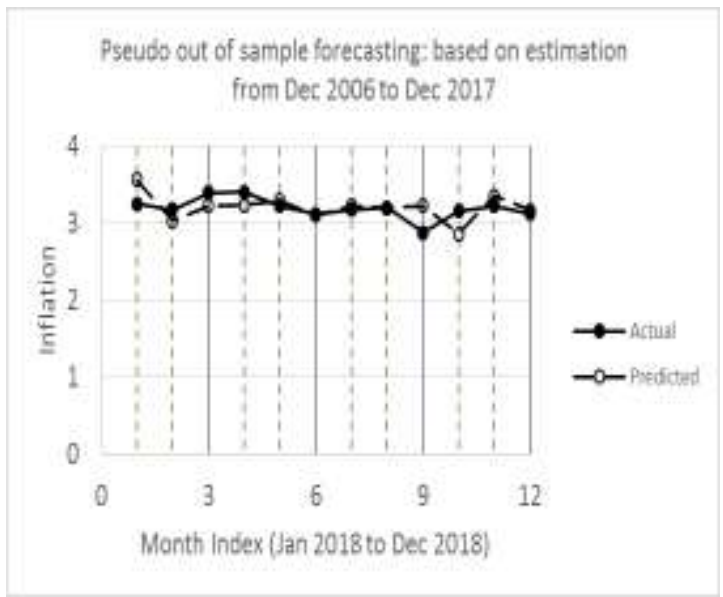

Figure 7. Inflation Forecasting Using ANN2: DS2.

From figure 8 , we can observe that the ANN3 model can forecast well the inflation of January, February, March, April, May, June, July, and August 2018. In September and October the forecasted values deviate from the actual values. These results demonstrate similar pattern as those in figures 5 and 7 .

Table 5 summerized each ANN model performance indicator. From table 5 it is obvious that the ANN3 forecasts inflation better than the ANN2. Notice that both ANN2 and ANN3 have the same structure with two hidden neurons, because according to our works, they provided better performances than with one hidden neuron.

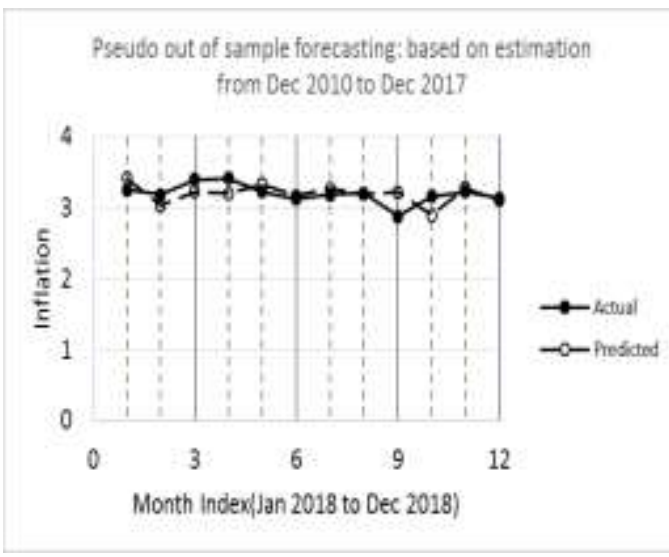

Figure 8. Inflation Forecasting Using ANN3:

DS3.

However, according to our investigations, the ANN1 is better having one hidden neuron than two neurons.

Table 5. Forecasting Performances of ANN Models

\begin{tabular}{cccc}
\hline $\begin{array}{c}\text { Performance } \\
\text { Index }\end{array}$ & \multicolumn{3}{c}{ ANN models } \\
\hline RMSE & 0.235 & 0.186 & 0.166 \\
MPE & -1.578 & -0.511 & -0.020 \\
\hline
\end{tabular}

Source : Data Processed

Now, let's we compare the ARIMA models with the ANN models by analyzing its respective RMSE and MPE. From table 3 and table 5, the results show that the ANN models outperform the ARIMA models in each respective series. For example, ANN3 provides RMSE of 0.166 whereas ARIMA3 produces RMSE of 0.182 . The ratio of RMSE between ANN3 and ARIMA3 is 0.91. Table 5 summarize ratio of RMSE and ratio of MPE between ANN models and ARIMA models. Less than one ratio indicates that the ANN model provides better performance than the corresponding ARIMA model. The smaller the ratio is the better. Thus, 
our results are consistent with previous investigations conducted in (Saeed Moshiri and Norman Edward Cameron, 2000) and (Emi Nakamura, 2005). Notice that our ARIMA models differ from their autoregressive models in terms of number of input variables and their lags.

From table 6, with regard to RMSE, further analysis reveals that Ratio 1 is the smallest value among all the ratio values. This result indicates that the performance enhancement by ANN is more significant when there exists steeper changes of variable.

Table 6. Ratio of Performance Index Between ANN and ARIMA Models

\begin{tabular}{lccc}
\hline \multirow{2}{*}{$\begin{array}{l}\text { Performance } \\
\text { Index (PI) }\end{array}$} & \multicolumn{3}{c}{ PI Ratio = ANN/ARIMA } \\
\cline { 2 - 4 } & Ratio 1 & Ratio 2 & Ratio 3 \\
\hline RMSE & 0.51 & 0.96 & 0.91 \\
MPE & 0.53 & 0.69 & 0.04 \\
\hline
\end{tabular}

Source : Data Processed

Our ARIMA models and ANN1 model accidently, has the same structure of the ARIMA model proposed in (Suparti et al., 2014) and the ANN model developed in (Warsito and Mukid, 2015). But our other two ANN models i.e. ANN2 and ANN3 models are different from them. Moreover, we developed different ARIMA models and ANN models which are more suitable for other time frames which encompase more recent data of inflation. Recall that ARIMA3 provides better forecasting performance than ARIMA2, and ANN3 gives better performance than ANN2. By analyzing our results of different time frames, we may be able to draw some new information/knowledge concerning Indonesia economics trend.

We know that Bank Indonesia has been implementing Inflation Targeting Framework (ITF) as a framework to implement monetary policy since 2005. Under the ITF, Bank Indonesia explicitly announces the inflation target to the public and all the monetary policy is determined to achieve the target. The ITF was adopted to replace money base targeting. Money base targeting was replaced as it failed to manage soaring annual inflation rate during the 1997 financial crisis.

Previously, two articles have been publised by other scholars which addressed economic issues on inflation inertia and inflation persistence in Indonesia. They used time series data that partly covered the period after implementation of the ITF. Recall that (Rizki E. Wimanda et al., 2011) used Indonesian inflation monthly data from $1980: 1$ to $2008: 12$ to conduct the study and they concluded that Indonesia's inflation possessed considerable inertia. More recent publication (Faisal Rachman, 2016) showed that Bank Indonesia's explicit inflation target was less reliable or it was outperformed by the backward looking variables at all forecast horizons.

He conducted a naive, univariate, and multivariate time-series models with an out-ofsample forecast evaluation period of January 2014 to December 2016. He used time series data from the period of January 1969 to December 2013 for the univariate model. All the variables used in the multivariate model are from the period of January 1996 to December 2013. His results indicate that Bank Indonesia has not succeed in managing inflation expectation near the targeted level.

Now, let's recall Table 2. The decrease of value in parameter $a_{1}$ in each model series indicates that Indonesia's inflation is less affected by short term lagged inflation (backwardlooking) variables in more recent series compared to older series. In other words, the inflation is becoming less persistence in recent years. Notice that our study uses three time series data sets: the data set 1 (DS1) covers from 2006:12 to 2014:12 (during the first and the second presidential terms of Susilo Bambang Yudhoyono), DS2 from 2006:12 to 2018:08 (covering 8 years in the presidential terms of Susilo Bambang Yudhoyono and 4 years in the first presidential term of Joko Widodo), and DS3 from 2010:12 to 2018:12 (covering 4 years in the second presidential term of Susilo Bambang Yudhoyono and 4 years in the first presidential term of Joko Widodo). 
All the data sets were selected to completely cover periods after implementaion of the ITF. Our finding implies that Bank Indonesia is heading to the right direction in terms of anchoring inflation expectation to the desired level. The reason why our finding is true can be attributed to many things, in which future research is required to appropriately pinpoint which policy significantly contributes to the trend towards forward looking inflation. A lot of policies have been implemented since 2006 to the end of 2018 in Indonesia. President Jokowi's policies to manage inflation can be attributed to the low and stable inflation in recent 4 years: import of key goods when necessary to control inflation, infrastructures development to ease logistics and transportation of goods, active market operations to control prices of essential goods, establishment of local government inflation controlling teams and the central government inflation controlling team, and others. Therefore, the low inflation persistence in recent years may be related to the stable low inflation rate in the last 4 years, and this acheivement may be attributed to the well coordinated policies and actions between Bank Indonesia, the central government, and local governments throughout the country.

However, due to uncertainty in the global market (i.e trade war between USA and the People Republic of China, the Federal Open Market Committee (FOMC) refusal to reduce interest rate despite the pressure from President Trump, the European Central Bank (ECB) reducing interest rate and questions regarding Bank of Indonesia action to maintain or reduce interest rate), we may see more variability in inflation that can result in Bank Indonesia's failure to achieve its Inflation Targeting Framework.

\section{CONCLUSION}

In terms of the trend of Indonesia's inflation, we found an interesting finding, that is, short-term lagged-inflation variables have lesser influence in more recent series in comparison to the older one. Future research can continue this finding and analyze the reason why there is such phenomenon.

Our comparison shows that ANN models outperform ARIMA models, this is showed by its respective Root Mean Square Error, as RMSE in the ANN models have a lower value compared to the ARIMA models. As such, ANN models are more reliable to forecast inflation in comparison to ARIMA models. Forecasting performance enhancement contributed by ANN model is more significant when there exists steeper change in the time series variabel.

\section{REFERENCES}

Aloysius Deno Hervino, 2015. A hybrid model of new Keynesian Phillips Curve: An application in Indonesia. J. Econ. Bus. Account. Ventura 18, 311-316. https://doi.org/10.14414/jebav.v18i3.502

Badan Pusat Statistik [WWW Document], n.d. URL https://www.bps.go.id/statictable/2014/09/ 26/915/tingkat-inflasi-tahun-ke-tahungabungan-82-kota-sup-1-sup-2012-100-.html (accessed 12.27.18).

BI [WWW Document], n.d. URL https://www.bi.go.id/id/moneter/inflasi/dat a/Default.aspx (accessed 12.27.18).

Bunyamin, Nevi Danila, 2011. Estimated Inflation in Indonesia Using Box Jenkins Methodology. Media Ris. Business Manaj. 11 (1), 71-87.

Deni Sri Haryati, Nuzulia Intan Maulida, Ika Oktafianingsih, Septi Diana Sari, Shinta Apriliawati, 2014. Analysis of Inflation Pre and Post the Monetary Crisis in the Indonesian Economy. Econ. Dev. Anal. J. 3 (4), 393-401.

Emi Nakamura, 2005. Inflation forecasting using a neural network. Econ. Lett. 86, 373-378. https://doi.org/10.1016/j.econlet.2004.09.00 3

Faisal Rachman, 2016. Is Inflation Target Announced by Bank Indonesia the Most Accurate Inflation Forecast? Econ. Finance Indones. 62, 98-120.

Idah Zuhroh, Hendra Kusuma, Syela Kurniawati, 2018. An approach of Vector Autoregression Model for inflation analy- sis in Indonesia. J. Econ. Bus. Account. Ventura 20, 261-268. https://doi.org/10.14414/jebav.v20i3.1019

James H. Stock, Mark W. Watson, 1998. A Comparison of Linear and Nonlinear 
Univariate Models For Forecasting Macroeconomic Time Series. NBER Work. Pap. No 6607.

Norman R. Swanson, Halbert White, 1997. A Model Selection Approach to Real-Time Macroeconomic Forecasting Using Linear Models and Artificial Neural Networks. Rev. Econ. Stat. 79(4), 540-550.

Reza Siregar, Gulasekaran Rajaguru, 2005. Sources of variations between the inflation rates of Korea, Thailand and Indonesia during the post-1997 crisis. J. Policy Model. 27, 867-884.

Rizki E. Wimanda, Paul M. Turner, Maximilian J.B. Hall, 2011. Expectations and the inertia of inflation: The case of Indonesia. J. Policy Model. 33, 426-438.

Saeed Moshiri, Norman Edward Cameron, 2000. Neural Network vs Econometric Models in
Forecasting Inflation. J. Forecast. 19, 201-217. Suparti, Budi Warsito, Moch. Abdul Mukid, 2014. The Analysis of Indonesia Inflation Data Using Box-Jenkins Models 6.

Suparti, Faridatus Sa'adah, 2015. Data Analysis on Indonesian Inflation Using the Model Autoregressisve Integrated Moving Average (ARIMA) with the addition of Outliers. Media Stat. 8, 1-11.

Ulfatul, I., 2017. The Analysis of Monetary Transmission Mechaniscm by Expectation Patterns in Influencing the Inflation. Econ. Dev. Anal. J. 6, 412-419.

Warsito, B., Mukid, M.A., 2015. Performance of neural network model in forecasting Indonesian inflation. Proc. IConSSE FSM SWCU 103-108. 